EESTI NSV TEADUSTE AKADEEMIA TOIMETISED. XV KÖIDE:

FOUSIKA-MATEMAATIKA- JA TEHNIKATEADUSTE SEERIA, 1966, NR. 1

ИЗВЕСТИЯ АКАДЕМИИ НАУК ЭСТОНСКОН ССР. ТОМ ХV СЕРИЯ ФИЗИКО-МАТЕМАТИЧЕСКИХ И ТЕХНИЧЕСКИХ НАУК. 1966, № 1

И. КЛЕСМЕНТ, А. КАСБЕРГ, О. ЭЙЗЕН

\title{
ОПРЕДЕЛЕНИЕ ГРУППОВОГО СОСТАВА СМОЛ И МАСЕЛ МЕТОДОМ ТОНКОСЛОЙНОЙ ХРОМАТОГРАФИИ
}

В последнее время при анализе органических соединений вместо бумажной хроматографии начали широко применять тонкослойную хроматографию - разделение веществ в тонком слое адсорбента. В основном этот метод используют для разделенгя и определения индивидуального состава микроколичеств полярных веществ, содержащих гетероатомы. Значительно реже он применяется для аналнза углеводородов, например ароматических соединений $\left[{ }^{1},{ }^{2}\right]$.

Помимо анализа смесей с малочисленными компонентами, названный метод прмменен для выделения из сложных смесей отдельных компонентов и для разделения групп соединений. Так, тонкослойную хроматографию использовали для характеристики группового состава $\left[{ }^{3}\right]$ и процессов старения смазочных масел [4], а также для установления антиоксидантов в них $[5,6]$. Метод применялся и для определения каменноугольных и разных видов древесных смол $[7,8]$.

Из названных работ, имеющих качественный характер, следует, что в тонком слое разделяются углеводородные группы: парафины, нафтены и ароматические соединения. Отсюда возникает мысль о возможности использования тонкослойной хроматографии для определения количественного группового состава разных смол и масел нефтяного происхождения, а также продуктов термического разложения топлива. В последние. 10-15 лет с этой целью использовали хроматографию в колонках. Но этот метод требует сравнительно много времени, в течение которого малогтабильные вещества могут изменяться. Расход материалов также значителен. Тонкослойный метод лишен этих недостатков.

Метод тонкослойной хроматографии может быть с успехом применен для получения количественных или полуколичественных результатов колориметрическими, радиометрическими, препаративными и другими способами $\left[{ }^{10},{ }^{11}\right]$. По точности результатоз: самый эффективный из них - препаративная тонкослойная хроматография, где количество разделяемого вещества составляет от нескольких десятков милиграммов $\left[{ }^{12}\right]$ до десяти граммов $\left.{ }^{13}\right]$. Большая часть препаративных рабөт посвящена разделению индивидуальных веществ.

В первой части данной работы, посвященной разработке метода тонкослойного определения группового состава смол, изучалась зависимость между величиной поверхности пятна на слое и количеством: вещества в нем. Хотя таким способом получают только полуколичественные результаты, он лучше других по скорости анализа. Применялись пластинки размером $12 \times 18$ см, толщина адсорбента - незакрепленного слоя окиси алюминия составляла 0,5 мм [11]. Әлюент - петролейный эфир, фракция $60-80^{\circ}$ С. Для детектирования вецеств использовали пары олеума. В случае насыщенных соединений, после воздействия парами $\mathrm{SO}_{3}$, пластинки нагревали в сушильном шкафу при $200^{\circ}$. 
В случае закрепленного слоя хорошим реактивом на углеводороды является также раствор пятихлористой сурьмы []. Сначала селективность разделения изучали на индивидуальных веществах. В таблице 1 приведены $R_{f}$ этих соединений, полученные в двух параллельных опытах. Результаты показывают, что кислородные соединения разделяются хорошо, а углеводороды - несколько хуже.

Далее изучалась возможность определения группового состава по величине поверхности пятен. При этом использовались разные фракции сланцевой смолы, кипящие в пределах 200-350․ Масла (2-5 мг) наносили на пластинку

$R_{f}$ индивидуальных соединений в тонком слое окиси алюминия

\begin{tabular}{l|c|c}
\hline \multirow{2}{*}{ Соединение } & \multicolumn{2}{|c}{$R_{f}$} \\
\cline { 2 - 3 } & Oпыт 1 & Опыт 2 \\
\hline & & \\
н-Додекан & 0,96 & 0,97 \\
1-Гексадецен & 0,94 & 0,95 \\
Дициклогексил & 0,93 & 0,93 \\
Декалин & 0,90 & 0,92 \\
Тетралин & 0,83 & 0,87 \\
Нафталин & 0,77 & 0,77 \\
Метилциклогексанон & 0,27 & 0,30 \\
Ацетофенон & 0,33 & 0,32 \\
Бензофенон & 0,32 & 0,33 \\
2-Нафтол & 0,09 & 0,08 \\
Резорцин & Н а м с т е \\
& \multicolumn{2}{|c}{}
\end{tabular}
калиброванными стеклянными капиллярами. После элюирования петролєйным эфиром разделенные пробы детектировали парами олеума. При этом образовалось 6-10 разноцветных пятен, поверхность которых уменьшалась или увеличивалась в зависимости от изменения температуры кипения смолы.

Известно, что между величиной поверхности пятна и логарифмом количества вещества в нем существует линейная связь [14]. В настоящей работе для изучения количественной зависимости изменяли количество вещества и в каждом опыте измеряли планиметром поверхности пятен. Выяснилось, что таким способом трудно получить количественные результаты; причиной неточности является разная скорость реакции отдельных групп при детектировании. Однако для быстрой приблизительной оценки состава масла этот метод можно все же использовать. При параллельном разделении на пластинке масла неизвестного состава и пробы с известным групповым составом легко сравнить содержание каждой группы.

С целью получения точных количественных результатов, разработку метода продолжали, применяя препаративный способ.

Для препаративного разделения больших количеств вещества (до 10 г) используют пластинки размером $20 \times 100$ см с толщиной слоя 5 мм [13]. Так как для определения группового состава можно обойтись и значительно меньшим количеством материала, нами использовались пластинки $24 \times 24$ см, толщина незакрепленного слоя скиси алюминия была 2 мм [15]. Методика анализа представлена на примере разделения одной фракции сланцевой смолы (продукты перегонки сланца в туннельных печах), кипящей при атмосферном давлении в пределах 285-296․ Узкокипящая фракция была выбрана в данном случае для более полной характеристики разделения методом газо-жидкостной хроматографии.

Разделяемое масло (неразбавленное) наносили на стартовую линию (1 cм от края пластинки) микрошприцем емкостью 100 мкл. Элюирование петролейным эфиром продолжалось менее часа. Для отметки полос разделенного вещества пластинку осмотрели в ультрафиолетовом свете. Отмеченные полосы окиси алюминия собирали с пластинки в маленькую ловушку струей воздуха водоструйного насоса. Адсорбент насыпали в 


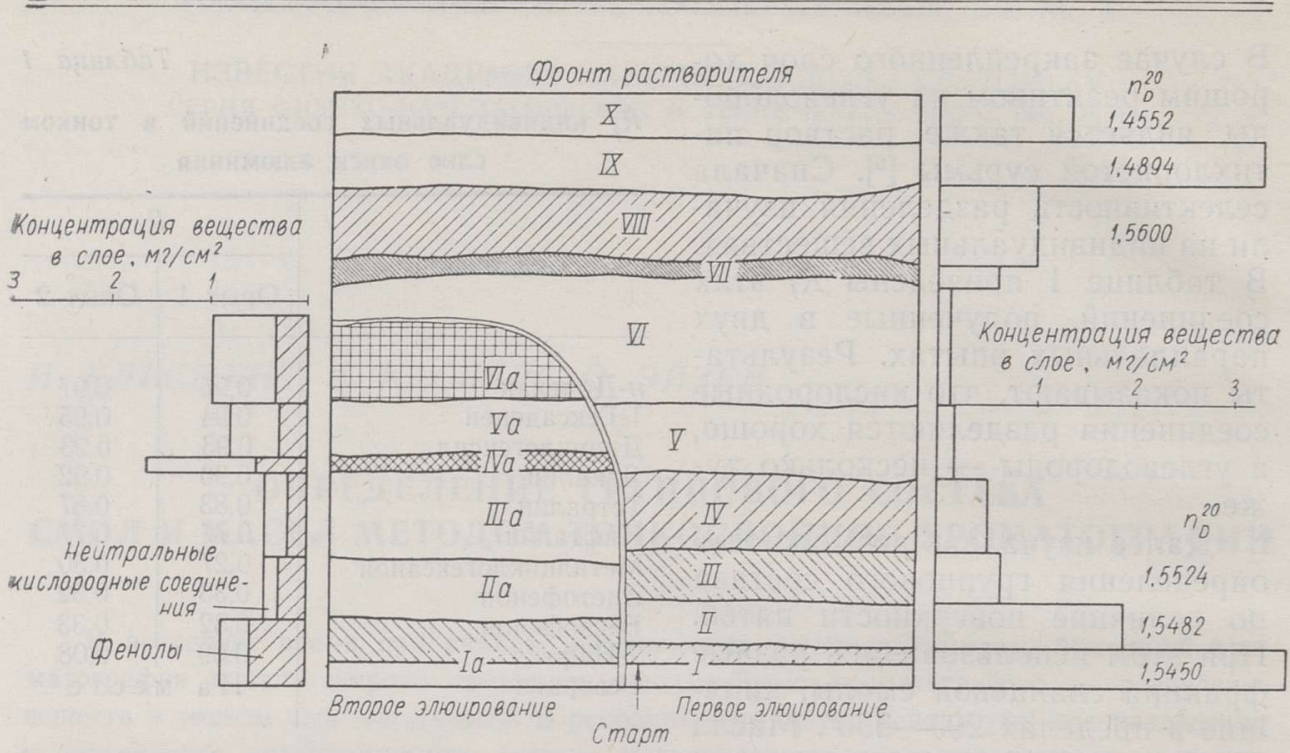

Рис. 1. Тонкослойные хроматограммы фракции сланцевой смолы. Правая часть хроматограммы (полосы I-X) получена однократным элюированием петролейным эфиром, левая часть (полосы Ia-VIa) представляет ту же хроматограмму после вторичного элюирования хлороформом-этилацетатом.

стеклянные фильтровальные воронки. Для вымывания углеводородов использовали ацетон, кислородных соединений - этиловый спирт. Растворитель ( 20 мл) собирали в маленькие колбочки со стеклянными шлифами, которые взвешивали на аналитических весах. Растворитель отгоняли путем нагрева на инфракрасной лампе, остатки его испаряли в вакууме водоструйного насоса. После взвешивания определяли показатели преломления и, в случае надобности, производили газохроматографический анализ.

Для определения максимального количества раздєляемого вещества, на пластинки наносили соответственно по 0,$12 ; 0,25 ; 0,50$ и 1,00 г смолы. После хроматографирования при осмотре пластинок в ультрафиолетовом свете выяснилось, что четкость разделения на трех первых пластинках одинакова, а на последней несколько хуже. Поэтому в следующих опытах разделяли в среднем 0,50 г смолы.

Результаты разделения фракции сланцевой смолы вышеописанным способом приведены в табл. 2 (опыт 1) и на рис. 1 (правая сторона). После элюирования на пластинке при осмотре в ультрафиолетовом свете были видны полосы I-X, которые на рис. 1 отмечены как область «первого элюирования».

Полосы I-VI (кислородные соєдинения) имели разные оттенки цвета; в начале хроматограммы количество полос было столь велико, что практически невозможно было выделить все отдельно.

Полоса VII сильно флуоресцировала, и вещество, выделенное из элюата, было кристаллическим, что указывает на присутствие в нем ароматических соединений с конденсированными ядрами. Полоса VIII флуоресцировала значительно слабее; ее показатель преломления говорит о том, что в ней были алкилароматические соединения. (стальная часть хроматограммы (до конца пластинки), содержащая олефины, нафтены, парафины, не флуоресцировала. Для определения местонахождения олефинов пластинку ставили на 30-60 сек в закрытый сосуд, содержащий пары брома. После десорбции избытка брома на пластинке 
обнаруживалась полоса олефинов, имеющая слабо-розовую окраску. Детектирование таким способом нежелательного влияния на результаты анализа не оказывало.

Фракции VIII, IX и X имели бромные числа соответственно 29, 63 и 18. Әти данные, а также показатели преломления фракций указывают на нечеткое разделение неароматических углеводородов. При этом, однако, следует отметить, что в высокомолекулярной области ни один хроматографический метод не дает хорошего разделения этих групп.

На рис. 2 изображены газо-жидкостные хроматограммы тонкослойных фракций VIII, IX и X в полярнсй колонке (жидкая фаза - полиэтиленгликоль 4000).

Из рисунка видно, что состав фракции VIII резко от-

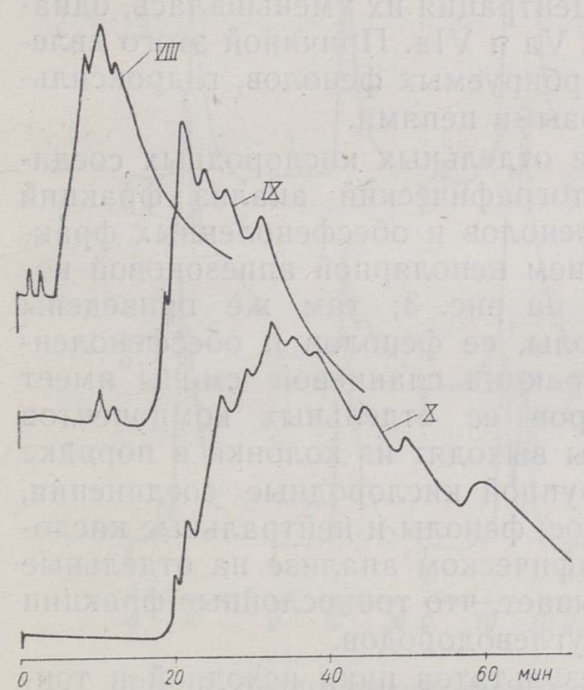

Таблиц̧а 2

Материальный баланс разделения фракции сланцевой смолы в тонком слое окиси алюминия

\begin{tabular}{|c|c|c|c|}
\hline \multirow{2}{*}{ Показатели } & \multicolumn{3}{|c|}{ № опыта } \\
\hline & 1 & 2 & 3 \\
\hline $\begin{array}{l}\text { Количество смолы, } \\
\text { мг } \\
\text { Выход, мг } \\
\text { Выход, вес. \% }\end{array}$ & $\begin{array}{r}490,5 \\
468,0 \\
95,7\end{array}$ & $\begin{array}{r}472,5 \\
451,0 \\
95,0\end{array}$ & $\begin{array}{r}519,2 \\
507,5 \\
97,6\end{array}$ \\
\hline Номера полос & \multicolumn{3}{|c|}{$\begin{array}{c}\text { Распределение вещества } \\
\text { в полосах, } \%\end{array}$} \\
\hline $\begin{array}{c}\text { I, Ia } \\
\text { II, IIa } \\
\text { III, IIIa } \\
\text { IV, IVa } \\
\text { V, Va } \\
\text { VI, VIa } \\
\text { VII } \\
\text { VIII } \\
\text { IX } \\
\text { X }\end{array}$ & $\begin{array}{r}22,2 \\
13,1 \\
4,5 \\
4,7 \\
1,6 \\
1,8 \\
1,4 \\
14,3 \\
24,4 \\
12,0\end{array}$ & $\begin{array}{c}(8,0) \\
(4,2) \\
(5,8) \\
(6,3) \\
(9,1) \\
(12,9) \\
1,2 \\
13,1 \\
26,5 \\
12,9\end{array}$ & $\begin{array}{c}(8,6) \\
(4,1) \\
(5,6) \\
(6,7) \\
(8,4) \\
(12,6) \\
2,3 \\
15,3 \\
26,4 \\
10,0\end{array}$ \\
\hline
\end{tabular}

* Результаты, показанные в скобках, получены двухкратным элюированием.

личается от следующих, газохроматографические характеристики которых близки. Количество компонентов во фракциях настолько велико, чтто отдельные пики не выделяются.

Қак выясняется из рис. 1, где отмечена также концентрация вещества в слое, при элюировании петролейным эфиром кислородные соединения и углеводороды отделяются хорошо, обе

\footnotetext{
Рис. 2. Газо-жидкостные хроматограммы тонкослойных фракций VIII, IX и X. Условия хроматографирования: хроматограф «Пай» с радиоактивным детектором; длина колонки - 1,2 м; неподвижная фаза - полиэтиленгликоль 4000 , $20 \%$ от носителя - целлита 545 ; хроматографирование велось при $175^{\circ}$; расход аргона $60 \mathrm{~m} /$ мин.
}

группы сосредоточены в противоположных сторонах пластинки. Середина пластинки почти пустая. Такое распределение смолы наводит на мысль о возможности использовать пустое место на пластинке для дополнительного разделения кислородных соединений более полярным растворителем.

При двойном элюировании вещество разделяли сперва петролейным 
эфиром, как описано выше, после чего отмечали на пластинке углеводородные полосы. При вторичном элюировании использовали смесь хлороформа и этилацетата $(9: 1)$; элюирование прекращали после того, как расстояние между фронтом растворителя и полосой полициклических углеводородов (сильно флуоресцирующая полоса VII) достигало 1 сл.

На рис. 1 (в левом нижнем углу) показано, как выглядела вторично элюированная область в ультрафиолетовом свете. Там же представлена концентрация вещества на пластинке. Материальный баланс двух параллельных опытов с вторичным элюированием представлен в табл. 2 (опыты 2 и 3). После вторичного элюирования кислородные соединения также разделились на шесть полос (полосы Ia-VI). Полоса IVa имела интенсивную красную окраску, и концентрация вещества в ней была высокой.

Основной целью вторичного элюирования было изучить возможность отделить таким путем фенолы от нейтральных кислородных соединений. Фракция содержала 18,0\% фенолов. Известно, что гидроксильные группы адсорбируются сильнее, чем карбонильные [ $\left.{ }^{9}\right]$, которые являются огновной частью нейтральных кислородных соединений сланцевой смолы. На рис. 1 изображено количественное распределение кислородных соединений в слое. Видно, что при втором элюировании произошло известное концентрирование соединений у стартовой линии и фронта растворителя. Для выяснения распределения фенолов хроматографические фракции Ia-VIa разбавляли бензолом и выделяли из них фенолы 10\%-ным $\mathrm{NaOH}$. Баланс кислородных соединений проверяли также отдельным двухкратным хроматографированием фенолов и обесфеноленной части исходной фракции смолы. Результаты - содержание фенолов в хроматографических фракциях кислородных соединений - приведены на рис. 1. Из рисунка видно, что разделение кислых и нейтральных соединений нечеткое. Фракции Іа и ІІа состояли преимущественно из фенолов, в последующих фракциях концентрация их уменьшалась, однако они присутствовали еще в фракциях Va и VIa. Причиной этого явления может быть присутствие слабоадсорбируемых фенолов, гидроксильная группа которых экранирована боковыми цепями.

Для выяснения четкости разделения отдельных кислородных соединений в слое производили газохроматографический анализ фракций Ia-VIa, а также выделенных из них фенолов и обесфеноленных фракций. Анализ проводился с использованием неполярной апиезоновой колонки. Результаты анализа приведены на рис. 3; там же приведены хроматограммы исходной фракции смолы, ее фенолов и обесфеноленной части. Так как анализируемая фракция сланцевой смолы имеет узкие пределы кипения, давление паров ее отдельных компонентов мало отличается, поэтому и компоненты выходят из колонки в порядке их полярности - сперва отдельной группой кислородные соединения, потом углеводороды. Как и в тонком слое, фенолы и нейтральные кислородные соединения при газохроматографическом анализе на отдельные группы не разделялись. Рисунок показывает, что тонкослойные фракцин кислородных соединений не содержат углеводородов.

С целью облегчения обсуждения результатов пики исходной и тонкослойных фракций на рис. 3 отмечены соответствующими номерами. Пики фенолов на хроматограммах четкие, количество их небольшое в первых фракциях присутствуют один-два основных компонента. Заслуживает внимания обстоятельство, что газохроматографические характеристики фенолов и нейтральных кислородных соединений близки: в отдельных полосах их количество равно, и на хроматограмме они также лежат близко. 
В данном случае газохроматографическое разделение, так же как и в тонком слое, происходит в основном по полярности компонентов, и оба анализа во многом дают совпадающие результаты. Қомпоненты, которые в полярном слое сильно адсорбируются, быстро выходят из полярной газохроматографической колонки. Здесь бывают также исключения: пик 4 содержит несколько компонентов, которые распределяются между полосами IIIa и VIa.

Результаты анализа показывают, что четкость разделения кислородных соединений в тонком слое не уступает четкости газовой хроматографии компоненты разделились на индивидуальные соединения. Разделение углеводородов было хуже, но его можно улучшить, применяя в качестве адсорбента силикагель вместо окиси алюминия. На силикагеле углеводороды сильнее адсорбируются, что позволяет полнее использовать поверхность пластин-
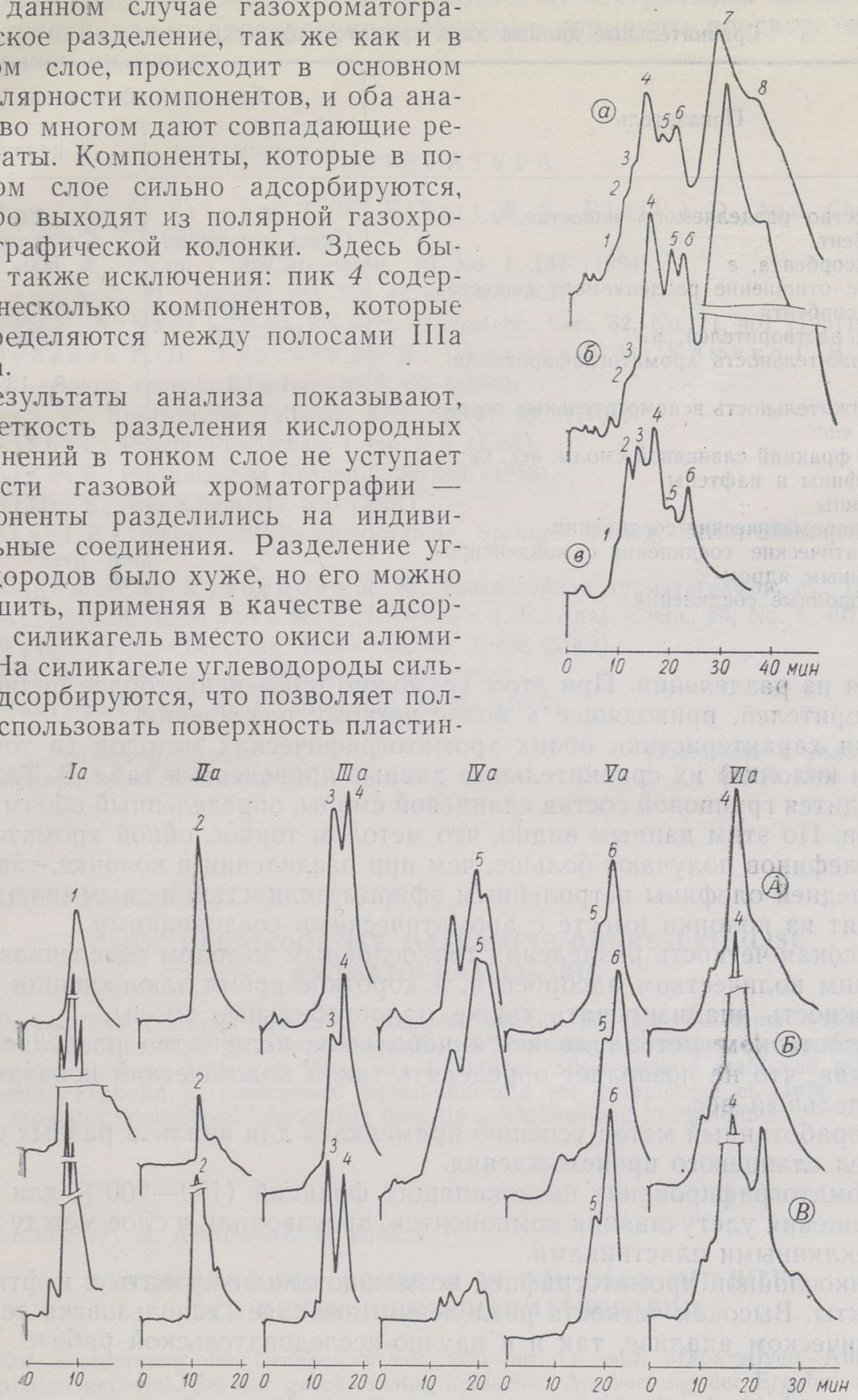

Рис. 3. Газохроматографическая характеристика тонкослойного разделения кислородсодержащей части сланцевой смолы. Вверху - хроматограммы: $a$ - исходной фракции; б - обесфеноленной исходной фракции; в - суммарных фенолов фракцин. Внизу - хроматограммы тонкослойных фракций: $A$ - исходные; $D$ - обесфеноленные; $B$ - фенолы. Условия хроматографирования: хроматограф «Пай»; длина колонки - 1,2 $м$; неподвижная фаза - апиезон $L, 15 \%$ от носителя - хрожосорба $W$; хроматографирование велось при $200^{\circ}$; расход аргона $60 \mathrm{M} \Omega /$ MUн. 
Сравнительные данные двух хроматографических методов

\begin{tabular}{|c|c|c|}
\hline \multirow{2}{*}{ Показатель } & \multicolumn{2}{|c|}{ Хроматографирование } \\
\hline & в тонком слое & в көлонке \\
\hline $\begin{array}{l}\text { Количество разделяемого вещества, } 2 \\
\text { Адсорбент } \\
\text { Вес адсорбента, г } \\
\text { Весовое отношение разделяемого вещества } \\
\text { и адсорбента } \\
\text { Расход растворителей, мл } \\
\text { Продолжительность хроматографирования, } \\
\text { час } \\
\text { Продолжительность вспомогательных опера- } \\
\text { ций, час } \\
\text { Состав фракций сланцевой смолы, вес. \%: } \\
\text { парафины и нафтены } \\
\text { олефины } \\
\text { алкилароматические соединения } \\
\text { ароматические соединения с конденсиро- } \\
\text { ванным ядром } \\
\text { кислородные соединения }\end{array}$ & $\begin{array}{l}0,5 \\
\text { Окись алюмнния } \\
80 \\
1: 160 \\
150-200 \\
1-1,5 \\
5 \\
10 \\
26 \\
16 \\
2 \\
46\end{array}$ & $\begin{array}{l}20 \\
\text { Силикагель. } \\
500 \\
1: 25 \\
2000 \\
8-12 \\
5 \\
7 \\
17 \\
27 \\
49\end{array}$ \\
\hline
\end{tabular}

ки для из разделения. При этом возможно применение более полярных растворителей, приводящее к более четкому разделению.

Для характеристики обоих хроматографических методов (в тонком слое и колонке) их сравнительные данные приведены в табл. 3. Там же приводится групповой состав сланцевой смолы, определенный өбоими методами. По этим данным видно, что методом тонкослойной хроматографии олефинов получают больше, чем при разделении в колонке, так как в последней олефины петролейным эфиром полностью не вымываются и выходят из колонки вместе с ароматическими соединениями.

Высокая четкость разделения тонкослойным методом обеспечивается большим количеством адсорбента, а короткое время элюирования дает возможность анализировать также малостабильные смолы.

Недостатқом метода является небольшое каличество разделяемого вещества, что не позволяет определять такой классический показатель, как удельный вес.

Разработанный метод успешно применялся для анализа разных смолЕ и масел сланцевого происхождения.

Хроматографирование низкокипящих фракций $\left(150-200^{\circ}\right)$, для предотвращения улетучивания компонентов, производили в слое между двумя стеклянными пластинками.

Тонкослойной хроматографией возможно анализировать и нефтяные продукты. Высокая четкость разделения позволяет использовать ее как в техническом анализе, так и в научно-исследовательской рабөте.

\section{Выводы}

1. Разработан метод тонкослойной хроматографии для определения группового состава смол и масел, который по быстроте и четкөсти разделения превышает колоночную хроматографню.

2. Полярные соединения (кислородные, азотистые) разделяются в; слое на индивидуальные соединения. 
3. Фенолы не отделяются в адсорбенте от нейтральных кислородных соединений, для их определения необходимо применять предварительную промывку щелочью.

Л И Т Е Р А Т Р А

1. Sawicki E., Stanley T. W., Elbert W. C., Pf a ff J. D., Anal. Chem., 36, No. 3, 497 (1964).

2. B e r g A., L a m J., J. Chromatog., 16, No. 1, 157 (1964).

3. Crump G. B., Nature, 193, No. 4816, 674 (1962).

4. Rey E., Erh a r t L., Bull. Schweiz. electrotehn. Ver., 52, No. 11, 401 (1961).

5. З убкова Н. Д., Т урский Ю. И., Генкина В. И., Ключко Г. В., Хим. и технол. топлив. и масел, № 8, 60 (1964).

6. R e y E., Electrotechn. Zeitschr., 13B, No. 11, 299 (1961).

7. S t a hl E., Pharm. Rundschau, 1, No. 2, 1 (1959).

8. S t a hl E., Parfümerie u. Kosmetik, 39, 561 (1958).

9. St a h 1 E., Ang. Chem., 73, 646 (1961).

10. Stahl E., Dünnschicht-Chromatographie, Springer Verlag, Berlin-Göttingen-Heidelberg, 1962 .

11. Ахрем А. А., К узн ец ов а А. Қ., Тонкослойная хроматография, М., 1964.

12. Millett M. A., Moore W. E., S a e ma n J. F., Anal. Chem., 36, No. 3, 491 (1964).

13. $\mathrm{H}$ a $\mathrm{l} \mathrm{p}$ a a $\mathrm{p} \mathrm{H}$., Chem. Ing. Techn., 35 , No. 7,486 (1963).

14. S e her A., Microchim. Acta, No. 2, 308 (1961).

15. Mistryukov E. A., J. Chromatog., 9, 311 (1962).

Ннститут химии

Академии наук Эстонской ССР
Поступила в редакцию 24/III 1965

\section{KLESMENT, A. KASBERG, O. EISEN}

\section{OLIDE GRUPIKOOSTISE MÄĂRAMINE ŌHUKESEKIHILISE KROMATOGRAAFIA ABIL}

Preparatiivseil alumiiniumoksiidi plaatidel lahutati $500 \mathrm{mg}$ õli tema grupikoostise määramiseks. Tulemuste gaasikromatograafilisel kontrollimisel selgus, et hapnikuühendid lahutatakse öhukeses kihis individuaalsete ühenditeni. Süsivesinikud eralduvad mõnevõrra halvemini. Fenoolid ja neutraalsed hapnikuühendid eri gruppidesse ei jaotu. Ohukeses. kihis kromatografeerimisel lahutatakse ühendid selektiivsemalt kui kolonnis.

\section{KLESMENT, A. KASBERG, O. EISEN}

\section{BESTIMMUNG DER GRUPPEN IN DEN ÖLEN MIT HILFE DER DUNNSCHICHT-CHROMATOGRAPHIE}

Zur Bestimmung der Gruppen wurde $500 \mathrm{mg}$ Öl auf präparativen Aluminiumoxidplatterı getrennt. Bei der gaschromatographischen Auswertung der Ergebnisse wurdebestimmt, dass die Sauerstoffverbindungen bis $\mathrm{zu}$ individuellen Verbindungen verteilt werden, während die Trennung der Kohlenwasserstoffe nicht so gut ist. Phenole und neutrale Sauerstoffverbindungen werden nicht in getrennte Gruppen verteilt. Die Selektivität der Trennung in der dünnen Schicht ist besser als in der Kolonne. 